\title{
Birth weight, education, environment, and lung function at school age: a community study in an alpine area
}

\author{
P. Lercher*, R. Schmitzberger**
}

\begin{abstract}
Birth weight, education, environment, and lung function at school age: a community study in an alpine area. P. Lercher, R. Schmitzberger. (CERS Journals Ltd 1997.

ABSTRACT: Our aim was to assess the effect of birth weight, gestational age, predispositions, education, housing and environmental factors on indices of lung function and to evaluate selective interactions among the main predictors.

We studied schoolchildren (aged 7.5-12 yrs) in a cross-sectional survey of 13 small alpine communities in Tyrol (Austria). Data were collected retrospectively from self-administered questionnaires $(n=796,85 \%$ response), public records and lung function testing ( $\mathrm{n}=\mathbf{7 5 2}, \mathbf{8 0 \%}$ response).

In the multivariate analysis it was found that a low birth weight (LBW), a low length of maternal education, a smaller gestational age, and a larger family size were all negatively associated with most lung function measures. Additionally, three significant interactions (birth weight with maternal education, birth weight with gestational age; and birth weight with family size) were observed. This implies that children of an LBW with mothers having a low level of education have a forced expiratory volume in one second (FEV1) value $148 \mathrm{~mL}$ lower than average values. Children born at term with an LBW have a $140 \mathrm{~mL}$ lower mean FEV1 value, and children of LBW from larger families display a $123 \mathrm{~mL}$ lower mean estimate of FEV1. However, subgroups were small ( $n=26,17$ and 27, respectively).

The results support low birth weight as a significant predictor of decreased lung function at school age. However, the size and the direction of the association may differ depending on the levels of the interacting variables. Eur Respir J 1997; 10: 2502-2507.
\end{abstract}

*Institute of Social Medicine, University of Innsbruck, Austria. **Dept of Pediatrics, University Clinic of Innsbruck, Austria.

Correspondence: P. Lercher Institute of Social Medicine Sonnenburgstrasse 16

A-6020 Innsbruck

Austria

\section{Keywords: Education}

family size

gestation

housing

low birth weight

Received: August 51996

Accepted after revision July 51997
With increasing evidence, low birth weight (LBW) has been reported to be associated with reductions in lung function in childhood, in both clinical [1-5] and population based studies $[6,7]$. A large retrospective cohort study has demonstrated a significant link between LBW and a reduced adult lung function [8], and led to the "programming hypothesis" [9]. However, these clinical studies often consisted of small samples, with infants selected because of a marked LBW. Often there was only a poorly defined or no control group at all. This makes it difficult to assess whether the reported effects are due to more severe neonatal respiratory illness, more extensive (or changing) treatment, preterm birth or LBW. In two major population based studies, different perinatal predictors and analytical methods were used [6, 7]. Moreover, affected lung function indicators and affected groups were inconsistent in both studies. A recent case-control study has challenged the relationship between LBW and later lung function impairment [10]. In addition, sufficient evidence has been gathered, showing that perinatal indicators (LBW, preterm delivery or preterm birth) and lung function are likewise associated with dispositional factors, environmental, and socioeconomic conditions [11-14]. However, the interrelationships of these factors have not yet been sufficiently studied $[13,15]$. Because inheritance at birth, education, life-style and behaviour, environmental and socioeconomic circumstances are believed to interrelate in a complex manner [15], it seems insufficient to treat these determinants in the analysis only as confounders (by simple adjustment). Additionally, a careful evaluation of potential interactions within this group of "independent" variables is required.

For this purpose, we used data from a cross-sectional study of schoolchildren that we had originally collected to assess the potential impact of traffic pollution relative to inherited, social and environmental factors in a rural and mountainous area of the Austrian Alps [16].

\section{Subjects and methods}

\section{Study population and sites}

A complete cohort of second, third and fourth grade schoolchildren (aged 7.5-12 yrs, $n=796$, overall participation $85 \%$ ) were recruited from seven "traffic exposed" communities with an average traffic density of over 10,000 vehicles·day ${ }^{-1}$ and six "unexposed" communities, chosen from adjacent areas with local traffic levels below 5,000 vehicles $\cdot$ day $^{-1}$. Overall participation ranged $71-100 \%$. Participation in lung function testing was slightly lower ( $n=752,80 \%$ overall participation). Exclusion criteria for site selection were: existence of point sources of industrial pollution; landfills or waste sites; 
and $\mathrm{SO}_{2}$ concentrations above $30 \mu \mathrm{g} \cdot \mathrm{m}^{-3} \cdot \mathrm{yr}^{-1}$. Thus, the study sites can be considered as representative for rural, alpine communities without pollution other than by road traffic. For the present analysis only children aged $\leq 11$ yrs were used ( $n=744$ for lung function, $n=787$ overall). Children in the final multivariate models $(n=644)$ did not differ from the participants overall. Altitude of study sites varied $500-1350 \mathrm{~m}$. A dichotomized category $(<1,000$ versus $\geq 1,100 \mathrm{~m}$ ) was used in this analysis. Topographically, "exposed" sites were generally situated in the larger valleys at a lower altitude while the "unexposed" sites were located in narrower valleys at a higher altitude or so called "middle mountain areas". As residential mobility in this area is very low and $>90 \%$ of the children have lived in their village since birth, the occurrence of an illness bias as a result of selective mobility is unlikely.

Basic data on air pollutants $\left(\mathrm{SO}_{2}, \mathrm{NO}_{2}, \mathrm{O}_{3}\right)$ were available from nearby monitoring sites and supplemented with additional measurements (four times 14 day sampling of $\mathrm{NO}_{2}$ and $\mathrm{SO}_{2}$ exposure by Palmes tubes at 15 locations and a continuous day-time exposure profile for $\mathrm{NO}_{2}, \mathrm{SO}_{2}$ and hydrocarbons by a mobile monitoring bus). It was found that the World Health Organization (WHO) Air Quality Guidelines were never exceeded. Exposure assignment of schoolchildren was based on $\mathrm{NO}_{2}$ as an indicator pollutant at their home address, because the "traffic exposed" area differed from the "unexposed" only by levels of exposure to $\mathrm{NO}_{2}$ (ranging 14-28 $\mu \mathrm{g}$. $\mathrm{m}^{-3}$ versus $4-10 \mu \mathrm{g} \cdot \mathrm{m}^{-3}$ ).

\section{Questionnaire information}

A standardized questionnaire completed by the mother (a mixture of questions from standard questionnaires) provided a wide range of information on family history (asthma, hayfever), the home environment (home size, crowding, type of floor, type of heating, pets, current parental smoking), child behaviour (outdoor activities: $\geq 4$ versus $<4 \mathrm{~h} \cdot$ day $^{-1}$ ), parental education, and area of work. Respiratory illnesses (asthma, acute and chronic bronchitis), hayfever, and eczema were based on doctors' diagnoses. "Wheezing" was evaluated by an additional short questionnaire [17]. The resulting scores were dichotomized (three or more positive items = "hyperreactive") for analysis. Additionally, a dichotomous "illness summary variable" was created (fulfilling one of the following conditions: asthma, acute or chronic bronchitis, "hyperreactive", "recurrent colds"). "Recurrent colds" was assessed by a five-point scale ("In general, has your child been prone to colds/respiratory infections"). The upper two categories ("rather" and "strongly") were used in the creation of the dichotomous "illness" variable.

"Maternal education" was assessed according to the Central Bureau of Statistics, based on the number of years in school. For the purpose of this study maternal education was dichotomized ( $>9$ or $\leq 9$ yrs of education: basic versus additional education). "Family size" was defined by the number of family members currently living in the same home. Birth weight and "gestational age at birth" were obtained from "mother-child passports" (a state supported healthcare service booklet with gynae- cologist's and paediatrician's entries). Entries on "gestational age" were mainly based on the last menstrual period and supplemental clinical assessment of physical characteristics of the newborn (e.g. loss of vernix). Early ultrasound examination was only available for one third of the sample at this time. Conventional definitions were adopted for LBW $(<2,500 \mathrm{~g})$ and preterm birth (<37 completed weeks).

\section{Lung function}

Flow volume curves were obtained by a computerized pneumotachograph (Multi Spiro PC, Medical Equipment Designs Inc., San Clemente, CA, USA). The associated software ensured excellent co-operation by displaying a birthday cake with burning candles on the screen. The stronger the expiration the easier it was to blow out the candles. Throughout testing the children sat and wore a nose clip. The testing standards of the American Thoracic Society were applied [18]. Two trained physicians performed the measurements after daily calibration of the spirometer. The tests were conducted in groups of three. After a practice blow, at least three further attempts were made (no limitation on number of blows). The three best blows were saved and evaluated for reproducibility (5\% criterion). From the acceptable blows the one with the largest sum of forced vital capacity (FVC) and forced expiratory volume in one second (FEV1) was chosen as the best blow and used to extract the data. FVC, FEV1, peak expiratory flow (PEF), and forced expiratory flows at 25 (MEF25), 50 (MEF50) and $75 \%$ (MEF75) of FVC were extracted for this analysis. Anthropometric data were obtained on the same day and conducted without shoes: height was measured with a portable stadiometer to the nearest $1 \mathrm{~cm}$ and weight was measured to the nearest $1 \mathrm{~kg}$ with the subject lightly clothed. A calibrated portable scale (calibration class 4; Soehnle Acurata, Soehnle-Waagen GMBH and Co., Murrhardt/Württ, Germany) was used.

\section{Statistical analysis}

Basic description of dichotomous data and assessment of confounders and potential effect modifiers were carried out by binomial tests and stratified $2 \times 2$ table analysis with Mantel-Haenszel techniques. Univariate and bivariate analysis of continuous variables were conducted by unpaired Student's t-tests and regression analysis. Extensive regression diagnostics were performed to assess the distribution of the continuous variables and the fit of the various models. Transformation of variables was not necessary. Standardization (age, length, weight) was performed separately for each sex based on the regression formulas of NEUberger et al. [19]. Each index of pulmonary function was analysed separately by multiple linear regression methods. A basic set of predictors (LBW or preterm birth, mother's length of education, smoking prevalence, illness, firstborn, altitude, family size, living space, type of floor, type of heating, farming, asthma history, highway or $\mathrm{NO}_{2}$ ) were used in the first instance. A limited set of biologically meaningful two-way interactions were then considered (birth weight 
with education, family size, and length of gestation; family history of asthma with altitude). Backwards elimination of confounders was applied and the most parsimonious model was chosen. The stability of the results was checked by a final sensitivity analysis. SAS 6.08 (SAS Institute, Cary, NC, USA) and S-PLUS 3.2 for Windows (MathSoft Inc., Seattle, USA) were used for statistical analysis.

\section{Results}

At the final analysis there were 644 schoolchildren remaining for whom information was available on all the variables. Table 1 gives the prevalences for the central categorical variables of this analysis broken down by sex and altitude. Overall, the prevalences for LBW and preterm delivery are in the upper range of reported values [13]. At higher altitudes, families are signi- ficantly larger, single room heating is more common, parents smoke less, and mothers help with farming. At lower altitudes (in the main valleys) maternal education is better but road traffic related pollution $\left(\mathrm{NO}_{2}\right)$ is higher. For comparison the last column provides the respective prevalences for the full sample of the 7.5-11 yr old children $(n=787)$. Table 2 shows the raw anthropometric and adjusted (for age, body height and weight) lung function data for the continuous variables. Overall, children with LBW exhibit lower values on both lung function and anthropometric indices, while children of mothers who have spent a longer period of time in education show a contrasting trend. An analysis of the relationships between maternal education or LBW and other exposure or outcome variables (potential confounding) used in the statistical models revealed: higher maternal educational level is significantly associated with a higher prevalence of only one child, higher $\mathrm{NO}_{2}$-exposure, more living space, and a nonsmoking household. On the

Table 1. - Prevalence of central study variables by sex and altitude

\begin{tabular}{|c|c|c|c|c|c|}
\hline \multirow[b]{2}{*}{ Variables groups } & \multicolumn{2}{|c|}{$\mathrm{Sex}^{+}$} & \multicolumn{2}{|c|}{ Altitude $^{+}$} & \multirow{2}{*}{$\begin{array}{c}\text { Full sample }^{++} \\
\mathrm{n}=787\end{array}$} \\
\hline & Male & Female & $<1100 \mathrm{~m}$ & $\geq 1100 \mathrm{~m}$ & \\
\hline \multicolumn{6}{|l|}{ Predispositions } \\
\hline Low birth weight $<2500 \mathrm{~g}$ & 6.9 & 7.1 & 6.8 & 8.0 & 7.2 \\
\hline Gestational age $<37$ weeks & 24.3 & 22.1 & 24.1 & 18.4 & 24.4 \\
\hline Birth order: firstborn & 43.1 & 43.2 & 44.0 & 37.9 & 42.5 \\
\hline Respiratory illness ever ${ }^{\dagger}$ & 22.9 & 20.4 & 22.6 & 16.1 & 21.0 \\
\hline Family history of asthma & 3.4 & 4.8 & 3.8 & 5.7 & 3.9 \\
\hline \multicolumn{6}{|l|}{ General environment } \\
\hline Altitude $>1100 \mathrm{~m}$ & 16.3 & 11.1 & - & - & 13.1 \\
\hline Mother involved in farming & 10.0 & 9.9 & $8.1 * * *$ & 21.8 & 10.4 \\
\hline $\mathrm{NO}_{2}$ exposure $>20 \mu \mathrm{g} \cdot \mathrm{m}^{-2}$ & 61.1 & 56.1 & $68.0 * * *$ & 0.00 & 58.4 \\
\hline \multicolumn{6}{|l|}{ Home environment } \\
\hline$>4$ persons $\cdot$ family $^{-1}$ & 54.0 & 49.7 & $49.0 * * *$ & 71.3 & 52.3 \\
\hline$<90 \mathrm{~m}^{2}$ living space & 22.6 & 16.7 & 20.8 & 13.8 & 22.1 \\
\hline Single room heating & 24.0 & 22.4 & $21.9 *$ & 32.2 & 24.0 \\
\hline Carpeted floor & 76.3 & 76.5 & 77.0 & 72.4 & 75.5 \\
\hline \multicolumn{6}{|l|}{ SES - behaviour } \\
\hline Maternal education $>9$ yrs & 37.8 & 37.7 & $40.0 * *$ & 23.0 & 36.6 \\
\hline Nonsmoking household & 53.7 & 57.5 & $53.7 *$ & 66.7 & 55.7 \\
\hline Outdoor activities $>4 \mathrm{~h}$ winter & 13.1 & 12.2 & 12.4 & 14.9 & 13.3 \\
\hline
\end{tabular}

Values are presented as percentages. $n$ : number of subjects; SES: socioeconomic status; $\uparrow$ : ever respiratory illness was defined as any presentation of asthma/wheeze, acute/recurrent bronchitis or recurrent colds. ${ }^{+}: \mathrm{n}=644 ;{ }^{++}: 7.5-11 \mathrm{yrs} ; *, * *, * * *: \mathrm{p}<0.05$, $\mathrm{p}<0.01, \mathrm{p}<0.001$ versus high altitude.

Table 2. - Anthropometric and lung function characteristics of the study sample by sex, maternal education, and low birth weight

\begin{tabular}{|c|c|c|c|c|c|c|}
\hline \multirow[b]{2}{*}{ Continuous variables } & \multicolumn{2}{|l|}{ Sex } & \multicolumn{2}{|c|}{ Maternal education } & \multicolumn{2}{|c|}{ Birth weight } \\
\hline & Male & Female & $>9$ yrs & 9 yrs & $<2500 \mathrm{~g}$ & $>2500 \mathrm{~g}$ \\
\hline \multicolumn{7}{|l|}{ Anthropometric data } \\
\hline Birth weight kg & $3.36(0.54)^{* *}$ & $3.24(0.50)$ & $3.31(0.53)$ & $3.30(0.52)$ & $2.12(0.32)^{* * *}$ & $3.40(0.41)$ \\
\hline Height $\mathrm{cm}$ & $136.3(6.9)$ & $135.6(7.4)$ & $136.8(7.0)^{* *}$ & $135.4(7.1)$ & $133.2(7.5)^{* *}$ & $136.2(7.1)$ \\
\hline Weight $\mathrm{kg}$ & $30.8(5.8)$ & $31.0(6.6)$ & $31.9(6.4)^{* * *}$ & $30.3(6.0)$ & $28.6(6.3)^{* *}$ & $31.1(6.1)$ \\
\hline $\begin{array}{l}\text { Body mass index } \\
\mathrm{cm} \cdot \mathrm{kg}^{-2}\end{array}$ & $16.7(2.2)$ & $16.5(2.1)$ & $16.9(2.2)^{* *}$ & $16.4(2.1)$ & $16.1(2.5)$ & $16.6(2.1)$ \\
\hline \multicolumn{7}{|c|}{ Pulmonary function data $^{+}$} \\
\hline FVC L & $2.11(0.26)^{* * *}$ & $1.96(0.25)$ & $2.08(0.27)^{* *}$ & $2.02(0.27)$ & $1.97(0.29)$ & $2.05(0.27)$ \\
\hline FEV1 L & $1.93(0.22)^{* * *}$ & $1.82(0.22)$ & $1.91(0.23)^{* *}$ & $1.86(0.23)$ & $1.82(0.24)$ & $1.88(0.23)$ \\
\hline PEF L & $4.19(0.39) * * *$ & $3.89(0.39)$ & $4.10(0.42)^{*}$ & $4.02(0.42)$ & $3.97(0.46)$ & $4.06(0.41)$ \\
\hline MEF25 L & $3.70(0.32)^{* * *}$ & $3.57(0.35)$ & $3.68(0.34)^{*}$ & $3.61(0.33)$ & $3.56(0.36)$ & $3.65(0.34)$ \\
\hline MEF50 L & $2.67(0.25)^{*}$ & $2.63(0.21)$ & $2.68(0.23)^{* *}$ & $2.63(0.22)$ & $2.60(0.24)$ & $2.66(0.23)$ \\
\hline MEF75 L & $1.44(0.10)^{* * *}$ & $1.36(0.11)$ & $1.42(0.11)^{*}$ & $1.40(0.11)$ & $1.38(0.12)$ & $1.41(0.11)$ \\
\hline
\end{tabular}

Values are presented as mean with SD in parenthesis. ${ }^{+}$: pulmonary function data has been adjusted for age, height and weight: mean age (SD): $9.3(0.85)$. ${ }^{*}, * * * * *: \mathrm{p}<0.05, \mathrm{p}<0.01, \mathrm{p}<0.001$. FVC: forced vital capacity; FEV1: forced expiratory volume in one second; PEF: peak expiratory flow; MEF25, MEF50, MEF75: maximal expiratory flow at 25, 50 and $75 \%$ of forced vital capacity. 
Table 3. - Final multiple regression model with forced expiratory volume in one second main predictors, and three interaction terms

\begin{tabular}{lccrr}
\hline Coefficient & Value & SEM & T-value & p-value \\
\hline (Intercept) & 1.560 & 0.111 & 14.0 & 0.000 \\
Birth weight kg & 0.094 & 0.033 & 2.9 & 0.004 \\
Maternal education $\geq 9$ yrs & 0.264 & 0.118 & 2.2 & 0.025 \\
Gestational age $\geq 37$ weeks & 0.298 & 0.118 & 2.5 & 0.012 \\
Family size $\geq 4$ members & -0.318 & 0.115 & -2.8 & 0.006 \\
Birth weight: education & -0.067 & 0.035 & -1.9 & 0.058 \\
Birth weight: preterm & -0.081 & 0.037 & -2.2 & 0.028 \\
Birth weight: family size & 0.084 & 0.034 & 2.5 & 0.015 \\
\hline
\end{tabular}

Values are adjusted for age, sex, height and weight according to Neuberger et al. [16].

Table 4. - Forced expiratory volume in one second $\left(\mathrm{FEV}_{1}\right)^{\star}$ and birth weight versus education, gestational age and family size

\begin{tabular}{|c|c|c|c|c|c|c|}
\hline & \multicolumn{2}{|c|}{ Maternal education } & \multicolumn{2}{|c|}{ Gestational age } & \multicolumn{2}{|c|}{ Family size } \\
\hline & $\geq 9 \mathrm{yrs}$ & $<9 \mathrm{yrs}$ & $\geq 37$ wks & $<37$ wks & $\geq 4$ & $<4$ \\
\hline Birth weight $\geq 2500 \mathrm{~g}$ & $\mathrm{n}=224$ & $\mathrm{n}=375$ & $\mathrm{n}=477$ & $\mathrm{n}=122$ & $\mathrm{n}=308$ & $n=291$ \\
\hline Mean FEV $1 \mathrm{~mL}$ & 1906 & 1871 & 1883 & 1888 & 1868 & 1900 \\
\hline $95 \% \mathrm{CI}$ & $1876-1936$ & $1848-1893$ & $1862-1903$ & $1848-1927$ & $1842-1895$ & $1875-1925$ \\
\hline Birth weight $<2500 \mathrm{~g}$ & $n=19$ & $n=26$ & $\mathrm{n}=17$ & $\mathrm{n}=28$ & $n=27$ & $\mathrm{n}=18$ \\
\hline Mean FEV 1 mL & 1954 & 1725 & 1743 & 1870 & 1745 & 1937 \\
\hline $95 \%$ CI & $1867-2039$ & $1634-1817$ & $1634-1852$ & $1779-1960$ & $1654-1836$ & $1841-2033$ \\
\hline
\end{tabular}

FEV1 values were adjusted for age, sex, height and weight according to NeUBERGER et al. [16]. n: number of subjects; 95\% CI: 95\% confidence interval.

other hand, higher levels of maternal education are significantly associated with fewer preterm deliveries, fewer households with single room heating, smaller families, children involved in fewer outdoor activities, and living at a lower altitude. LBW does not show any significant association except the strong logical link with preterm birth.

Multiple regression analysis of lung function measurements (table 3 ) revealed significant independent positive "main effects" for birth weight, length of maternal education, and preterm delivery with the large airway indicator FEV1. A negative effect is evident for family size. Practically identical results were obtained for the small airway indicator MEF75. Apart from minor differences, similar results were seen also with the other lung function indicators (FVC, PEF, MEF25 and MEF50). No significant effects on lung function could be observed for parental asthma, time spent outdoors, respiratory illnesses (asthma, bronchitis, recurrent colds, hayfever, wheezing), type of floor or heating, $\mathrm{NO}_{2}$ exposure, altitude or current amount of smoking in the household in all the analyses.

As the presence of relevant interactions (birth weight with preterm delivery, birth weight with family size, birth weight with education) impedes direct interpretation of the "main effects", the specific results of the interaction analysis are given in table 4 . Whereas a negative impact of LBW on lung function is not visible among children of well educated mothers (even with an average FEV1 value $48 \mathrm{~mL}$ higher than predicted values), the opposite is true for mothers having had a lower level of education, where the average FEV1 value is $146 \mathrm{~mL}$ lower than predicted. A similar modification of the "main effect" occurred with gestational age. Comparing the two birth weight groups with a lower gestational age, no obvious effect on FEV1 $(18 \mathrm{~mL})$ could be observed. However, among the children born at term, those with an LBW show significantly lower FEV1 values (140 $\mathrm{mL}$ ). A third modification of the association of birth weight with FEV1 does take place with the biosocial indicator "family size". In those in the larger family size category, the children with an LBW show a substantially smaller mean FEV1 value $(123 \mathrm{~mL})$ than those with normal birth weight. On the other hand, in the smaller sized families an LBW does not show such a negative impact (with an FEV1 value $37 \mathrm{~mL}$ higher than predicted).

\section{Discussion}

The results of this study suggest that an LBW, a low level of maternal education, and a larger family size are significantly associated with a decrease in the level of most lung function measures in children aged between 7.5-11 yrs.

Moreover, level of maternal education, family size and gestational age interact with birth weight. This reminds us to interpret the observed "main effects" only in the light of these interactions, as outlined in table 4.

The observed effect on lung function of LBW mimics the findings obtained in a larger population based study of a similar age range from the UK in 1993 [6]. Likewise, gestational age itself, another mentioned perinatal predictor of later respiratory health, did not show up as an overall significant predictor of possible longterm effects on lung function [6]. Though, the results of this study support a slight modification of this conclusion: an association was evident in the LBW group with birth at term. Our results are somewhat at variance with another population based study [7], which reported decrements in some lung function tests for premature girls only. Our results are also slightly in contrast with a recent case-control study [10] that found only a nonsignificant trend for an adverse effect on lung function of intra-uterine growth retardation in term babies 
by the age of 16 yrs. However, the trend moves in the same direction as in our study.

The results for an effect of LBW on lung function are also supported by more clinically oriented smaller studies, some with more stringent criteria for LBW [2-5]. In slight contrast to some of these studies and the larger population based studies, our study did find significant effects of LBW on a broad range of lung parameters. This fact counters arguments that have raised concern about single associations with FEV1, a flow index considered unreliable in this age group [10]. One reason for the better consistency may be, that adjustments were applied for a broader range of potential confounders than in any of the mentioned studies.

The reported association of maternal education with lung function is mainly supported by earlier British studies [12, 15]. However, most evidence stems from marked social class gradients in respiratory mortality and morbidity, which were mostly attributed to differentials in smoking prevalence, crowding, housing standards and other markers of poor environmental conditions $[13,15]$. While some of these conditions were differentially present in this sample, their contribution in the multivariate analysis was negligible and did not alter the coefficient for the level of maternal education itself. Likewise, this is also true for the social indicator family size. Although there is a significant association between family size and length of maternal education, our various sensitivity analyses have shown that family size is a factor in its own right, independently associated with lung function. Therefore, it must be speculated that other familial factors such as upbringing and living conditions, associated with length of maternal education, but not measured in this study, may have been responsible for the reported effect. Nevertheless, the underlying preventive factors remain to be discovered. Differential dietary habits (e.g. breast feeding versus formula feeding) and behavioural or cognitive factors in education may be reasonable candidates $[15,20,21]$ that should be considered in future studies.

This study has some methodological strengths: the population based sampling, the low mobility rates and the reasonable participation proportion make sure that selection factors are unlikely to play a biasing role. Birth weight data stem from medical records. Predispositional, environmental, housing, and behavioural factors were largely taken into account in the multivariate models. Furthermore, the reported associations were consistent across the set of measured lung function indicators.

However, the potential limitations that affect this study should be mentioned as well: the small samples left for the interaction assessment $(n=26$ for length of maternal education and LBW, $\mathrm{n}=17$ for age of gestation and $\mathrm{LBW}, \mathrm{n}=27$ for family size and LBW) require cautious interpretation. No information was available about the height of the mother, smoking and alcohol consumption during pregnancy, conditions that are established determinants of LBW and preterm delivery [11, 13, 15, 22]. Likewise, no account could be made for parity, perinatal treatment or lower respiratory tract infections during the first year. Finally, the inherent limitations of the cross-sectional design preclude cause and effect interpretation.
In conclusion, the results of this cross-sectional study support a possible negative impact of low birth weight on lung function in children at school age. Length of maternal education and family size seem to make independent contributions to lung function. However, the significant interactions with birth weight preclude a definitive conclusion for the "main effects", while the interactions themselves need confirmation from larger studies for the specific subgroup associations. Above all, this study shows the importance of screening more rigorously for differential effects within potentially susceptible groups defined by predispositions and environmental, behavioural or social conditions relevant to public health.

Acknowledgements: The authors would like to thank the mothers' of the study subjects and the teachers for their co-operation, the Government of Tyrol for financial support, P. Brussee, J. Hörtnagl, K. Rhomberg, A. SeidlBrodman, A. Weitenhiller for study co-ordination and implementation, and W.W. Kofler for institutional support. Several macros from F. Harrell helped with diagnostic plots and by-variable analyses.

\section{References}

1. Mansell AL, Driscoll JM, James LS. Pulmonary followup of moderately low birth weight infants with and without respiratory distress syndrome. J Pediatr 1987; 110: $111-115$.

2. Chan KN, Noble-Jamieson CM, Elliman A, et al. Lung function in children of low birth weight. Arch Dis Child 1989; 64: 1284-1293.

3. Tammela OK, Linna OV, Koivisto ME. Long-term pulmonary sequelae in low birth weight infants with and without respiratory distress syndrome. Acta Paediatr Scand 1991; 80: 542-544.

4. Kitchen WH, Olinsky A, Doyle LW, et al. Respiratory health and lung function in 8-year-old children of very low birth weight: a cohort study. Pediatrics 1992; 89: $1151-1158$.

5. Todisco T, de Benedictis FM, Iannacci L, et al. Mild prematurity and respiratory functions. Eur $J$ Pediatr 1993; 152(1): 55-58.

6. Rona RJ, Gulliford MC, Chinn S. Effects of prematurity and intrauterine growth on respiratory health and lung function in childhood. Br Med J 1993; 306: $817-$ 820.

7. von Mutius E, Nicolai T, Martinez FD. Prematurity as a risk factor for asthma in preadolescent children. $J$ Pediatr 1993; 123: 223-229.

8. Barker DJP, Godfrey KM, Fall C, et al. Relation of birth weight and childhood respiratory infection to adult lung function and death from chronic obstructive airways disease. Br Med J 1991; 303: 671-675.

9. Barker DJP. Mothers, Babies and Disease in Later Life. London, BMJ Publishing Group, 1994.

10. Matthes JWA, Lewis PA, Davies DP, et al. Birth weight at term and lung function in adolescence: no evidence for a programmed effect. Arch Dis Child 1995; 73: 231-234.

11. Brooke OG, Anderson HR, Bland JM, et al. Effects on birth weight of smoking, alcohol, caffeine, socioeconomic factors, and psychosocial stress. Br Med J 1989; 298: 795-801. 
12. Steinberg M, Becklake MR. Socio-environmental factors and lung function. S Afr Med J 1986; 70: 270274.

13. Kline J, Stein Z, Susser M. Conception to Birth. Epidemiology of Prenatal Development. New York, Oxford University Press, 1989.

14. Berkowitz GS, Papiernik E. Epidemiology of preterm birth. Epidemiol Rev 1993; 15: 414-443.

15. Power C, Manor O, Fox J. Health and Class: The Early Years. London, Chapman \& Hill, 1991.

16. Lercher P, Schmitzberger R, Kofler W. Perceived traffic air pollution, associated behaviour and health in an alpine area. Sci Total Environ 1995; 169: 71-74.

17. Kühr J, Hendel-Kramer A, Stephan V, et al. Epidemiologische Erfassung von Asthma bronchiale beim Schulkind. Pneumol 1989; 43: 703-709.
18. American Thoracic Society. Standardization on spirometry - 1987 update. Am Rev Respir Dis 1987; 136: $1285-1298$.

19. Neuberger M, Wiesenberger W, Kundi M, et al. FlußVolumen-Referenzwerte für Pflichtschüler. AtemwLungenkrkh 1993; 19: S87-S90.

20. Strachan DP. Causes and control of chronic respiratory disease: looking beyond the smokescreen. J Epidemiol Community Health 1992; 46: 177-179.

21. Rutter DR, Quine DL. Inequalities in pregnancy outcome: a review of psychosocial and behavioural mediators. Soc Sci Med 1990; 30: 553-568.

22. Peacock JL, Bland JM, Anderson HR. Preterm delivery: effects of socioeconomic factors, psychological stress, smoking, alcohol, and caffeine. Br Med J 1995; 311: 531-536. 